\title{
Les métaphores du virus COVID-19 dans les discours d'Emmanuel Macron et de Pedro Sánchez
}

\author{
Isabel NEGRO ALOUSQUE \\ Universidad Complutense de Madrid \\ inegro@ccee.ucm.es \\ https://orcid.org/0000-0002-5836-6166
}

\section{Resumen}

En las últimas décadas, la metáfora en el discurso especializado ha sido objeto de numerosas investigaciones. Desde una perspectiva cognitiva, el presente artículo analiza la conceptualización del virus COVID-19 en los discursos pronunciados por Emmanuel Macron, el presidente francés, y Pedro Sánchez, el presidente del Gobierno español, entre marzo y junio de 2020. El análisis revela una red de metáforas conceptuales que describen el virus como un ser animado o una catástrofe natural, así como las acciones para contenerlo como una guerra. Este marco metafórico desempeña tres funciones: (1) subrayar los efectos devastadores del virus; (2) inspirar coraje y esperanza; (3) apelar a la unión del país para frenar la pandemia.

Palabras clave: estudios cognitivos, discurso político.

\section{Résumé}

Au cours des dernières décennies, la métaphore dans les discours spécialisés a fait l'objet de nombreuses recherches. Prenant appui sur l'approche cognitive de la métaphore, cet article se propose d'analyser la conceptualisation du virus COVID-19 dans les discours prononcés par Emmanuel Macron, le Président de la République française, et Pedro Sánchez, le chef du gouvernement espagnol, entre mars et juin 2020. L'analyse permet de dégager un réseau de métaphores conceptuelles qui décrivent le virus comme un être animé ou une catastrophe naturelle, et l'action pour le contenir comme une guerre. Tout en soulignant les effets dévastateurs du virus, ce cadre métaphorique sert à inspirer le courage et l'espérance et à faire appel à l'union nationale pour enrayer l'épidémie.

Mots-clés : études cognitives, discours politique.

\footnotetext{
*Artículo recibido el 5/06/2020, aceptado el 4/03/2021.
} 


\begin{abstract}
In the last decades metaphor in specialized discourse has been vastly researched. Following a cognitive approach to metaphor, the present article seeks to analyze the conceptualization of COVID-19 disease in the speeches made by Emmanuel Macron, the French president, and Pedro Sánchez, the Spanish prime minister, between March and June 2020. The analysis reveals a network of conceptual metaphors which describe the virus as an animate being or a natural disaster, and action to stop its spread as a war. This metaphorical network has a threefold purpose: (1) to highlight the devastating effects of COVID-19; (2) to instil courage and hope; and (3) to make appeals for union in order to contain the pandemic.
\end{abstract}

Key words: cognitive studies, political discourse.

\title{
1. Introduction
}

Au cours des dernières décennies, la communication politique a été envisagée comme un type de discours (Chilton et Schäffner, 2002) remplissant une fonction rhétorique (De Landtsheer et Feldman, 2000 ; Feldman et De Landtsheer, 1998) et une fonction idéologique (Van Dijk, 2006 ; Wodak, 1989). De nombreuses études se sont penchées sur le rôle de la métaphore dans les différentes formes du discours politique (allocutions, manifestes des partis politiques, interviews, articles journalistiques, etc.). Les approches cognitive, discursive, sociolinguistique et pragmatique de la métaphore politique mettent en évidence ses différentes fonctions : cognitive, argumentative et rhétorique.

Cet article s'inscrit dans le cadre de la recherche sur le rôle de la métaphore dans la communication politique. Il porte sur l'utilisation de la métaphore dans un échantillon de discours d'Emmanuel Macron, le Président de la République française, et de Pedro Sánchez, le chef du gouvernement espagnol, au sujet du COVID-19, une maladie infectieuse causée par un coronavirus, qui est apparu à Wuhan (Chine) en décembre 2019. Depuis son apparition, le virus s'est propagé, touchant plus de 180 pays et devenant ainsi pandémique. Les mesures adoptées par les gouvernements dans le processus d'endiguement de la transmission de la maladie (confinement, mesures limitant les rassemblements et la mobilité) ont engendré une crise économique sans précédent marquée par la réduction de l'activité économique, la chute du produit intérieur brut, une crise de l'offre et de la demande, et des pertes d'emplois très significatives. Les gouvernements ont mis en place des plans d'aide nationale et des mesures de soutien à l'emploi, qui ont été annoncés par les chefs de gouvernement ou les présidents dans leurs discours. Ce sont ces discours que nous nous proposons d'examiner dans le but de repérer les métaphores renvoyant au virus et d'analyser leur fonction. À notre connaissance, la métaphorisation du COVID-19 n'a pas été étudiée jusqu'à présent. 
On y a fait tout simplement allusion dans des blogs, des émissions de radio ${ }^{1}$, des interviews $^{2}$ ou des articles de presse (par exemple, Cuenca, 2020).

L'analyse dégage un réseau de métaphores conceptuelles qui décrivent le virus comme un être animé ou une catastrophe naturelle, et l'action pour le contenir comme une guerre. L'hypothèse de cette recherche est que le choix de ces métaphores est motivé par l'intention communicative des locuteurs de souligner la gravité et les effets dévastateurs du COVID, d'un part, et d'inspirer le courage et faire appel à l'union nationale afin de pouvoir enrayer l'épidémie, d'autre part.

La première partie de cet article décrit le cadre théorique de notre recherche : la théorie conceptuelle de la métaphore, et les fonctions de la métaphore dans la communication politique. La deuxième partie présente la méthodologie et l'analyse des métaphores décrivant le virus.

\section{Cadre théorique}

Notre analyse repose sur la théorie de la métaphore conceptuelle mise en avant par Lakoff et d'autres chercheurs (Kövecses, 2002 ; Lakoff, 1987, 1989, 2006 ; Lakoff et Johnson, 1980,1999 ; Lakoff et Turner, 1989) dans le cadre de la linguistique cognitive.

Cette théorie conçoit la métaphore non comme un fait de langue, mais comme un processus cognitif qui structure la pensée et, par conséquent, le langage. Selon Lakoff et Johnson (1980: 15), "l'essence d'une métaphore est qu'elle permet de comprendre quelque chose (et d'en faire l'expérience) en termes de quelque chose d'autre ». Plus précisément, la métaphore peut être décrite comme un système de mappages ou mises en correspondance partielles (mappings) entre un domaine concret (le domaine source) et un domaine abstrait (le domaine cible). Par exemple, dans la métaphore conceptuelle LA POLITIQUE EST UN VOYAGE, l'objectif à atteindre est conçu comme la destination. Ainsi, dans le contexte de la crise catalane déclenchée par la proclamation d'indépendance de la Catalogne au Parlement régional en octobre 2017, les dirigeants séparatistes déclarent que la Catalogne marche vers un scénario d'indépendance. L'expression linguistique métaphorique (marcher) est la réalisation de surface indicatrice d'une métaphore conceptuelle.

Les métaphores imprègnent le discours politique, et leur rôle a été l'objet de nombreuses recherches (Chilton, 1996 ; Sharifian et Jamarani, 2013 ; Straehle et al., 1999). On peut distinguer trois fonctions de la métaphore politique : (1) cognitive ;

\footnotetext{
${ }^{1}$ La journaliste Catherine Voyer-Léger parle de la métaphore de la guerre dans son émission C'est fou sur Ici Radio Canada (https://ici.radio-canada.ca/premiere/emissions/c-est-fou/segments/chronique/161980/metaphores-coronavirus-covid-19-catherine-voyer-leger).

${ }^{2}$ Cécile Alduy, sémiologue et professeure de littérature à l'université de Stanford, parle de la métaphore guerrière dans une interview publiée à Libération le 30 mars 2020. Rony Brauman, ancien président de Médecins sans frontières, conteste l'utilisation de cette métaphore dans son livre livre Guerres humanitaires? Mensonges et intox (2018).
} 
(2) argumentative ; (3) rhétorique. Le rôle cognitif de la métaphore politique est postulé par les théoriciens cognitifs (Beer et De Landtsheer, 2004 ; Chilton et Ilyin, 1993 ; Semino et Masci, 1996 ; Straehle et al., 1999). La dimension cognitive comprend deux aspects. D'une part, la métaphore dans la communication politique est un moyen de conceptualiser et d'exprimer les thèmes politiques. Dans cette optique, la métaphore est un mécanisme permettant de construire la réalité politique (Graber, 1993). D’autre part, les métaphores politiques réifient les abstractions (Katz, 1996 ; Thompson, 1996). Comme le font remarquer Mio et Katz (1996 : 1), «la politique, étant une entité abstraite, s'appuie fortement sur les métaphores pour rendre les concepts plus appréhensibles".

Néanmoins, la métaphore politique ne contribue pas seulement à développer un cadre conceptuel pour la représentation des idées. Ainsi Charteris-Black (2004, 2005, 2009), Musolff (1998, 2000, 2004) et Musolff et Zinken (2009) proposent-ils une conception de la métaphore qui tient compte de ses dimensions discursives. Sous cet angle, la métaphore est tout d'abord un mode d'argumentation. Comme le fait remarquer Musolff (2004 : 39), « l'exploitation argumentative des métaphores conceptuelles dans le discours politique est illimitée ». Les métaphores politiques sont très efficaces dans la communication et l'explication des politiques. Dans la même veine, De Landtsheer (2009) et De Landtsheer et Koch (2005) affirment que la métaphore sert à communiquer une idéologie. Le terme idéologie doit être ici compris dans le sens suggéré par Kress et Hodge (1993 : 15) : "L’idéologie implique une présentation systématiquement organisée de la réalité ». Charteris-Black (2004 : 28) soutient que la métaphore est essentielle pour créer une telle présentation de la réalité. Troisièmement, la métaphore est un outil rhétorique dans la communication politique dans la mesure où elle cherche à éveiller les émotions du public.

\section{Corpus d'analyse et méthodologie}

Le corpus d'analyse est constitué d'un échantillon de discours prononcés par Emmanuel Macron et Pedro Sánchez entre mars et juin 2020. Les documents (textes ou vidéos) ont été tirés du site officiel de la Présidence de la République française (www.elysee.fr) et du site officiel de la Présidence du Gouvernement espagnol (www.lamoncloa.gob.es) respectivement.

L'échantillon est présenté ci-dessous :

- Discours de Macron :

1. Déclaration depuis l'EHPAD Péan à Paris (6 mars)

2. Allocution du 12 mars

3. Allocution du 16 mars

4. Déclaration depuis un centre d'hébergement réquisitionné pour accueillir des sans-abri (23 mars). 
5. Allocution à Mulhouse lors d'une visite à l'hôpital de champagne 25 mars

6. Déclaration depuis l'entreprise Kolmi-Hopen (31 mars)

7. Allocution du 13 avril

8. Déclaration à l'issue du Conseil Européen consacré à la lutte contre le COVID-19 (23 avril)

9. Communiqué de presse du Président de la République et du Premier ministre annonçant le plan de déconfinement (11 mai)

10. Message lors de la 73ème Assemblée mondiale de la Santé (18 mai)

- Discours de Pedro Sánchez :

Déclaration de l'état d'alarme sanitaire (13 mars)

Allocution du 21 mars

Conférence de presse lors de la réunion avec les présidents des gouvernements locaux (22 mars)

Allocution du 28 mars

Conférence de presse du 4 avril

Allocution du 12 avril

Conférence de presse du 18 avril

Conférence de presse au sujet du $3^{\mathrm{e}}$ prolongement de l'état d'alarme sanitaire (25 avril)

Allocution du 9 mai

Allocution du 23 mai

Sur cet échantillon deux types d'analyse ont été effectués : une analyse quantitative, et une analyse qualitative fondée sur le relevé de toutes les occurrences du terme virus dans les discours prononcés par Macron et Sánchez entre mars et juin 2020.

Nous avons d'abord repéré les expressions métaphoriques qui apparaissent dans le corpus. Afin de déterminer si les termes décrivant le virus étaient métaphoriques, nous avons appliqué la méthode MIPVU (Metaphor Identification Procedure VU University Amsterdam) développée par une équipe de linguistes dénommée le Pragglejaz Group22 (Steen et al., 2010) qui permet de repérer les métaphores dans un texte donné à partir du sens premier du mot tel qu'il est recensé dans le dictionnaire The Macmillan English Dictionary for Advanced Learners. Cette technique est fondée sur l'idée que le sens métaphorique d'un terme provient de l'écart sémantique entre le sens contextuel d'un mot (le sens qu'il prend dans un contexte particulier) et son sens premier, le sens littéral. Si le sens contextuel et le sens concret d'un terme sont suffisamment éloignés, le terme est métaphorique.

Suivant la méthode MIPVU, la première étape du repérage des expressions métaphoriques consiste à établir le sens du mot virus dans le contexte où il est employé. 
La deuxième étape vise à chercher le sens premier du mot virus. Le sens du mot français a été tiré du dictionnaire Larousse, et celui du mot espagnol du dictionnaire de la Real Academia Española (Diccionario de la Lengua Española). Selon le dictionnaire Larousse, le mot virus signifie "agent infectieux très petit, qui possède un seul type d'acide nucléique, A.D.N. ou A.R.N., et qui ne peut se reproduire qu'en parasitant une cellule».

Le Diccionario de la Lengua Española définit virus dans les termes suivants : "Organismo de estructura muy sencilla, compuesto de proteínas y ácidos nucleicos, y capaz de reproducirse solo en el seno de células vivas específicas, utilizando su metabolismo ». En essence, un virus est une particule microscopique infectieuse.

Dans une dernière étape, nous avons déterminé pour la plupart des occurrences du mot virus dans notre échantillon que le sens contextuel, tout en présentant une similitude avec le sens premier, est métaphorique.

Une fois repérées les expressions métaphoriques se rapportant au virus, nous les avons classées, d'après le domaine source dont elles relèvent, en cinq catégories : métaphores de la guerre, métaphores du voyage, métaphores de la Nation-famille, métaphores des animaux et métaphores des catastrophes naturelles.

Nous avons ensuite formulé les métaphores conceptuelles.

Cette étude décèle une conceptualisation semblable du virus dans les discours de Macron et de Sánchez, bien qu'il existe des différences concernant les réalisations des métaphores conceptuelles.

\section{Analyse des métaphores}

Notre analyse met en évidence la métaphorisation de la pandémie dans les discours de Macron et Sánchez. Le domaine cible «virus COVID-19» est conceptualisé en termes d'humain, animal ou catastrophe naturelle, et l'action pour contenir le virus est conçue comme une guerre.

Ces métaphores s'organisent dans un réseau métaphorique, comme le montre le tableau 1 : 


\begin{tabular}{|c|c|c|}
\hline \multicolumn{2}{|c|}{ MÉGAMÉTAPHORE } & SOUS-MÉTAPHORES \\
\hline \multirow{5}{*}{$\begin{array}{l}\text { LE VIRUS EST UN } \\
\text { ETTRE HUMAIN }\end{array}$} & \multirow[b]{2}{*}{ Dimension individuelle } & $\begin{array}{l}\text { LE VIRUS EST UN ENNEMI (métaphore insé- } \\
\text { rée dans la métaphore L'ACTION CONTRE } \\
\text { LE VIRUS EST UNE GUERRE) }\end{array}$ \\
\hline & & $\begin{array}{l}\text { Métaphores basées sur le schème du che- } \\
\text { min : } \\
\text { LE VIRUS EST UN ÊTRE QUI SE DÉPLACE } \\
\text { LE VIRUS EST UN ÊTRE QUI VOYAGE }\end{array}$ \\
\hline & \multirow{3}{*}{$\begin{array}{l}\text { Interaction avec l'envi- } \\
\text { ronnement } \\
\text { - Interaction avec l'en- } \\
\text { vironnement social : } \\
\text { êtres humains } \\
\text { - Interaction avec l'en- } \\
\text { vironnement naturel : } \\
\text { êtres animés } \\
\text { - Interaction avec l'en- } \\
\text { vironnement naturel : } \\
\text { phénomènes naturels }\end{array}$} & $\begin{array}{l}\text { LA NATION EST UNE FAMILLE QUI LUTTE } \\
\text { CONTRE LE VIRUS }\end{array}$ \\
\hline & & LE VIRUS EST UN ANIMAL \\
\hline & & $\begin{array}{l}\text { LE VIRUS EST UNE CATASTROPHE NATU- } \\
\text { RELLE }\end{array}$ \\
\hline
\end{tabular}

Tableau 1. La mégamétaphore LE VIRUS EST UN ÊTRE HUMAIN

et ses sous-métaphores dans les discours de Macron et de Sánchez

Plus précisément, on notera que les métaphores servant à décrire le COVID19 s'organisent dans un système cohérent de métaphores qui s'insèrent dans la mégamétaphore Chaîne des Êtres, un modèle culturel qui reflète la conceptualisation de la hiérarchie des êtres dans l'univers (Lakoff et Turner, 1989: 167). Au sommet de la hiérarchie se trouve l'être humain. Suivent ensuite les animaux et les plantes. Les positions inférieures sont occupées par les objets complexes et les phénomènes naturels. Chaque niveau se définit à l'aide des autres niveaux (Lakoff et Turner, 1989: 171) ; autrement dit, la hiérarchie des niveaux se définit en termes d'attributs : plus une entité possède d'attributs, plus elle tend à occuper les échelons du haut de la hiérarchie.

Suivant la hiérarchie établie par le modèle de la Chaîne des Êtres, les métaphores de notre corpus s'insèrent dans la mégamétaphore LE VIRUS EST UN ÊTRE HUMAIN. Le COVID-19 est tout d'abord apparenté à un être humain. Les êtres humains peuvent être considérés comme individus ou comme membres d'une collectivité. Lorsqu'ils sont considérés comme des individus, la conceptualisation du virus prend appui sur le schème du CHEMIN ${ }^{3}$. Ce schème rend compte de la description du virus comme un être humain qui se déplace d'un pays à l'autre.

\footnotetext{
${ }^{3}$ Les schèmes (image schemas), postulés par Lakoff (1987) et Johnson (1987), sont des structures conceptuelles qui organisent nos expériences quotidiennes.
} 
Lorsque les êtres humains sont considérés comme des membres d'une collectivité, Macron et Sánchez ont recours à l'environnement pour décrire le virus. L'interaction avec l'environnement social, avec d'autres êtres humains auxquels on est lié par des rapports d'affection ou de fraternité sous-tend la métaphore de la NATION-FAMILLE présente dans le discours de Sánchez. Alors que les autres métaphores du réseau décrivent des caractéristiques du COVID-19, cette métaphore conceptualise le peuple espagnol comme une famille dont les membres luttent ensemble contre le virus.

Lorsqu'il est question de l'interaction des êtres humains avec l'environnement naturel, l'attention est portée sur l'interaction avec d'autres êtres animés (des animaux) ou sur les effets des catastrophes naturelles telles qu'un tsunami ou un tremblement de terre.

Le cadre métaphorique présenté ci-dessus dégage les métaphores suivantes :

1. Métaphores liées à la conception de l'être humain comme individu

- LE VIRUS EST UN ÊTRE HUMAIN. Métaphore associée : L'ACTION POUR CONTENIR LE VIRUS EST UNE GUERRE.

- LE VIRUS EST UN ÊTRE HUMAIN QUI SE DÉPLACE

- LE VIRUS EST UN ÊTRE HUMAIN QUI VOYAGE

2. Métaphores liées à la conception de l'être humain en tant que membre d'une collectivité

- LA NATION-ÉTAT EST UNE FAMILLE

- LE VIRUS EST UN ANIMAL

- LE VIRUS EST UNE CATASTROPHE NATURELLE

\subsection{Métaphores de l'être humain-individu}

La métaphore LE VIRUS EST UN ÊTRE HUMAIN sert à présenter le virus comme l'ennemi dans une guerre :

(1) Estamos confinados para luchar contra el enemigo común.

[Nous sommes confinés pour lutter contre l'ennemi commun]

(2) Ahora Europa se enfrenta a un desafío distinto, que es librar una guerra contra un enemigo común, que está diezmando la salud de sus ciudadanos.

[L'Europe est maintenant confrontée à un autre défi : faire la guerre à un ennemi commun, qui ruine la santé de ses citoyens]

(3) Il y a quelques jours que nous sommes engagés dans une guerre, une guerre contre un ennemi invisible, le COVID-19.

Ces exemples montrent que la personnification du virus s'insère dans une métaphore qui assimile l'action contre le COVID-19 à une guerre. Cette métaphore dégage les mappages suivants :

a) L'action visant à freiner et éventuellement enrayer le COVID-19 est une guerre :

(4) Nous avons un combat contre le virus à mener. 
(5) Il faut continuer la lutte contre ce virus.

(6) Cuando la batalla se hace más intensa, es el momento de intensificar la lucha. [Quand la bataille devient plus intense, il est temps d'intensifier le combat]

b) Les citoyens et les gouvernants sont les soldats appelés à lutter contre le virus :

(7) Nous avons [...] des soignants qui sont au front chaque jour.

(8) La Nation tout entière est mobilisée.

(9) [...] toutes les capacités hospitalières nationales ainsi que le maximum de médecins et de soignants seront mobilisées. [...] Nous allons aussi mobiliser les étudiants, les jeunes retraités. [...] La mobilisation générale est également celle de nos chercheurs.

(10) Vous avez un Gouvernement qui est à la tâche, œuvrant pour trouver les solutions et se battant.

c) Le rôle que les citoyens jouent pendant l'épidémie de COVID-19 s'apparente à la position qu'ils occupent dans une bataille :

(11) Dans cette guerre, il y a en première ligne l'ensemble de nos soignants. [...] Je veux aussi saluer l'ensemble des femmes et des hommes qui sont en deuxième ligne [... Ce sont les femmes et les hommes qui transportent, qui hébergent, qui dépannent, qui nettoient, qui réparent. Ce sont nos agriculteurs, ce sont l'ensemble des femmes et des hommes qui sont dans le secteur de l'alimentation, des commerces de première nécessité, ce sont nos livreurs, nos caissiers et nos caissières [...] Et il y a la troisième ligne, celles et ceux qui peuvent télétravailler ou rester à la maison.

(12) Y hay muchos frentes en esa batalla. Por supuesto, está el frente de las administraciones públicas. [...] Ligado al frente de las administraciones, está el frente sanitario. Hay otro frente esencial, porque de la victoria en ese frente depende en buena medida todo lo demás, que es el confinamiento en las casas.

[Et il y a de nombreux fronts dans cette bataille. Bien sûr, il y a le front de l'administration publique. Lié au front des administrations il y a le front du personnel sanitaire. Il y a un autre front essentiel, car tout le reste dépend en grande mesure de la victoire sur ce front ; il est formé par ceux qui restent chez eux]

d) Le confinement et les mesures-barrière sont des actes de résistance contre le COVID-19 :

(13) Pero debemos resistir aún más para poder soportar el duro tramo que nos espera.

[Mais nous devons résister encore plus pour pouvoir supporter les difficultés qui nous attendent] 
(14) Y sólo hay un camino: sacrificio, resistencia y moral de victoria. Sacrificio para resistir, resistencia para vencer y victoria para vivir.

[Et il n'y a qu'un seul chemin : le sacrifice, la résistance et l'espoir de vaincre. Le sacrifice pour résister, la résistance pour gagner et la victoire pour vivre]

e) Les citoyens qui ne respectent pas les mesures de confinement sont les alliés du virus :

(15) Quien se crea al margen de la situación y pretenda seguir con su vida con normalidad, debe ser consciente de que se comporta como un aliado del virus.

[Toute personne qui ne se sent pas concernée et qui veut continuer à vivre normalement doit être consciente qu'elle se comporte comme un allié du virus]

f) Les moyens de faire face au virus sont des armes ou des stratégies employées dans la guerre contre le COVID-19:

(16) L'utilisation le plus large possible des tests est une arme privilégiée pour sortir au bon moment du confinement.

(17) [...] con la unidad de acción como la mejor arma para ganarle al COVID19.

[(...) avec l'unité d'action comme la meilleure arme pour battre le COVID19]

(18) [...] la estrategia definida por la Organización Mundial de la Salud para combatir el virus, y que consiste en tratar de contenerlo y frenar su propagación.

[(...) la stratégie définie par l'Organisation mondiale de la santé pour lutter contre le virus, qui consiste à essayer de le contenir et d'arrêter sa propagation]

g) L'endiguement de l'épidémie est la victoire dans la guerre contre le virus :

(19) Nuestra única opción es la victoria completa sobre el virus.

[Notre seule chance est la victoire absolue sur le virus]

(20) La victoria depende de cada uno de nosotros.

[La victoire dépend de chacun de nous]

(21) Venceremos al virus. [Nous vaincrons le virus]

(22) C'est cette France unie [...] qui, partout en France, se déploie avec force et qui nous permettra de gagner contre cet ennemi invisible, car il n'est pas invincible.

Les métaphores de la guerre ont des connotations négatives et positives. D’un côté, elles mettent en évidence le danger du virus; d'un autre côté, elles servent (1) à faire appel à l'union nationale et à faire taire les oppositions et les critiques (23-28) ; (2) à inspirer le courage et l'espérance (29-31) :

(23) Estamos todos unidos para combatir el virus.

[Nous sommes tous unis pour combattre le virus]

(24) [...] porque será unidos como resistiremos y venceremos al virus. 
$[(\ldots)$ car ce sera dans l'union que nous résisterons et que nous vaincrons le virus]

(25) C'est cette France fraternelle qui nous permettra de tenir et de vaincre.

(26) Toute la Nation est engagée dans ce combat. Chacun a un rôle à y jouer, parce que [...] dans cette guerre nous devons faire bloc, être unis [...] et tenir l'unité et le courage qui nous permettront de vaincre.

(27) No tengo ni tendré [...] otro enemigo que el virus.

[Je n'ai pas et n'aurai pas d'autre ennemi que le virus]

(28) Lorsqu'on engage une guerre, on s'y engage tout entier, on s'y mobilise dans l'unité.

(29) Estamos luchando contra un enemigo al que vamos a vencer.

[Nous luttons contre un ennemi que nous allons vaincre]

(30) Hemos comprobado que podemos lograrlo, que podemos arrancar victorias al virus.

[Nous avons prouvé que nous pouvons le faire, que nous pouvons vaincre le virus]

(31) No está cerca la victoria plena y completa, aún nos quedan momentos y tiempos duros que luchar, pero ya hemos empezado a ganar.

[La victoire pleine et entière n'est pas proche, nous avons encore des moments et des moments difficiles à combattre, mais nous avons déjà commencé à gagner]

D'autres métaphores reposent sur le schéma cognitif du CHEMIN : LE VIRUS EST UN ÊTRE HUMAIN QUI SE DÉPLACE, LE VIRUS EST UN ÊTRE HUMAIN QUI VOYAGE

La combinaison de la métaphore anthropomorphique et du schéma cognitif du CHEMIN (PATH) crée une métaphore qui assimile le virus à un être humain qui se déplace :

(32) El virus no se detiene. [Le virus ne s'arrête pas]

(33) Es el pueblo español el que ha hecho retroceder al virus.

[Ce sont les Espagnols qui ont fait reculer le virus]

(34) Grâce à vous, le virus a reculé. Mais il est toujours là.

Le schéma du CHEMIN, qui implique un mouvement métaphorique d'un lieu à un autre lieu, est constitué de trois éléments : un point de départ, un point d'arrivée et une direction. Les réalisations du schéma du CHEMIN que nous avons retrouvées dans notre échantillon focalisent la direction. Le virus est assimilé à un être humain qui voyage. La métaphore du voyage sert à décrire une caractéristique essentielle du virus, à savoir, sa propagation rapide. La propagation du COVID-19 est conçue comme le 
trajet du virus (35-36), chaque pays affecté par le virus étant un arrêt au cours du voyage (36) :

(35) El virus inició su viaje letal en Asia; se trasladó de inmediato a Europa, comenzando por Italia y España y continuando por el resto del continente.

[Le virus a commencé son voyage mortel en Asie ; il s'est immédiatement déplacé vers l'Europe, en commençant par l'Italie et l'Espagne et en continuant sur le reste du continent]

(36) La fatalidad ha dibujado un trayecto en el viaje mortal del virus que arranca en Oriente y ahora mismo está situado en Europa como una de las estaciones de tránsito antes de hacer nuevas escalas.

[La fatalité a tracé un chemin dans le voyage mortel du virus qui commence à l'Est et est situé maintenant même en Europe comme l'une des stations de transit avant de faire d'autres arrêts]

(37) Ignoramos todavia muchas de las cuestiones vinculadas con el virus. Una de ellas es cuál será la próxima estación de su tránsito en este viaje letal.

[Nous ignorons encore de nombreux problèmes liés au virus. L'un d'eux est de savoir quelle sera la prochaine station de son transit dans ce voyage mortel]

\subsection{Métaphores de l'être humain-membre d'une collectivité}

\subsubsection{LA NATION-ÉTAT EST UNE FAMILLE}

Dans son discours, Pedro Sánchez fait appel à l'union nationale pour faire face à l'impact du COVID au moyen de la métaphore LA NATION-ÉTAT EST UNE FAMILLE. La nation n'est pas une collectivité liée par des rapports de force, mais par des rapports de parenté (38) marqués par l'amour et la solidarité (39) :

(38) España es [...] una comunidad humana; las relaciones que nos unen se parecen a las que se dan en una familia.

[L'Espagne est [...] une communauté humaine ; les liens qui nous unissent ressemblent à ceux qui existent dans une famille]

(39) Toda la sociedad española ha actuado como una comunidad humana ligada por lazos de afecto y de cuidado.

[L'ensemble de la société espagnole a agi comme une communauté humaine liée par des liens d'affection et de soin]

\subsubsection{LE VIRUS EST UN ANIMAL}

Plusieurs expressions métaphoriques comparent le virus à un animal. Comme le remarque Köveczces (2002), le domaine source des animaux est souvent utilisé pour caractériser des entités abstraites. Sánchez utilise cette métaphore au début de la période de confinement pour avertir du risque de propagation du virus :

(40) El virus está al acecho. [Le virus est à l'affût] 
Le contact avec le virus est parfois apparenté à l'attaque d'un animal avec ses cornes (embestidas), ou ses dents (morsure). La comparaison du virus avec des expériences de douleur physique causée par les cornes ou les dents d'un animal souligne le caractère mortel du COVID-19, renforcé par l'adjectif brutal dans l'exemple (41) :

(41) Hemos contenido la embestida brutal de la epidemia.

[Nous avons contenu l'attaque brutale de l'épidémie]

(42) Cette ville [Mulhouse], ce territoire porte les morsures de celui-ci [le virus].

\subsubsection{LE VIRUS EST UNE CATASTROPHE NATURELLE}

Une série de métaphores présentent le virus comme un tremblement de terre (43) ou un tsunami (44-45). Dans l'exemple (45), l'apparition du COVID-19 en Europe est décrite comme l'arrivée des vagues d'un tsunami (embate) :

(43) Europa es el epicentro de la pandemia.

[L'Europe est l'épicentre de la pandémie]

(44) La gran ola de la pandemia ha sido superada.

[La grande vague de la pandémie a été surmontée]

(45) Hemos visto cómo todos los paises del mundo sufrian el embate de la pandemia. [Nous avons vu tous les pays du monde touchés par la pandémie]

La catégorisation du virus comme un tsunami sert également à décrire l'évolution de la pandémie, les résurgences du COVID-19 étant présentées comme les vagues d'un tsunami :

(46) Ahora va a llegar la ola. Los españoles tienen que estar unidos en sus casas mientras su país les protege, les cuida y combate esa ola con tesón.

[Maintenant, la vague va venir. Les Espagnols doivent être unis dans leurs foyers tandis que leur pays les protège, prend soin d'eux et lutte avec ténacité contre cette vague]

(47) Precipitarnos, relajarnos o desunirnos justo ahora tendría un resultado peor que devolvernos al punto de partida porque desencadenaría una segunda ola.

[Se précipiter, relâcher les mesures ou se désunir maintenant serait pire que de revenir au point de départ car cela déclencherait une deuxième vague]

(48) Sur le plan sanitaire, d'abord, tout est mis en œuvre pour que nos services de santé puissent faire face à la vague. naturelle :

Les effets de la pandémie sont apparentés aux dégâts causés par une catastrophe

(49) Un dia más para ayudar a vencer una guerra contra un enemigo criminal que arrebata vidas, que siembra devastación económica y también desolación humana. 
[Un jour de plus pour aider à gagner une guerre contre un ennemi criminel qui prend des vies, qui sème la dévastation économique et aussi la désolation humaine]

L'exemple ci-dessus montre que les associations négatives du domaine source servent à souligner l'impact humain et économique du virus.

Nous avons repéré plusieurs cas de superposition de deux métaphores, dont l'exemple (50) :

(50) Nadie puede ganar solo esta guerra, solo unidos venceremos al virus y a la devastación que amenaza dejar tras de sí.

[Personne ne peut gagner cette guerre seul, ce n'est qu'ensemble que nous vaincrons le virus et la dévastation qu'il menace de laisser derrière lui]

L'exemple susmentionné révèle la superposition des métaphores L’ACTION CONTRE LE VIRUS EST UNE GUERRE (ganar esta guerra, venceremos, enemigo) et LE VIRUS EST UNE CATASTROPHE NATURELLE (devastación).

L'analyse de ce système de métaphores montre que leur choix est motivé par l'intention communicative des locuteurs. D’une part, Macron et Sánchez visent à souligner la gravité du coronavirus et ses effets dévastateurs, ce qui explique l'utilisation de métaphores qui décrivent le COVID comme un ennemi ou un animal violent, de métaphores basées sur le schéma de CHEMIN, qui décrivent la propagation extrêmement rapide du virus, et de métaphores qui le présentent comme une catastrophe naturelle. D'autre part, Macron et Sánchez croient que l'impact du COVID requiert une réponse globale destinée à soutenir les actions du gouvernement. Ainsi les deux présidents ontils recours à la métaphore de la NATION-FAMILLE, qui renforce les liens entre les membres d'une collectivité nationale tout en faisant disparaître les différences politiques et sociales. Cette métaphore sert aussi à inspirer le courage et l'espérance en établissant des rapports de parenté marqués par la fraternité et la solidarité.

\subsection{Analyse quantitative}

Le relevé systématique des expressions métaphoriques renvoyant au virus dans les discours de Macron et Sánchez laisse voir qu'elles sont plus nombreuses dans les discours de Sánchez (117 contre 27 pour Macron).

La guerre constitue le domaine dans lequel Macron et Sánchez puisent le plus grand nombre de métaphores, comme le montre le graphique suivant : 


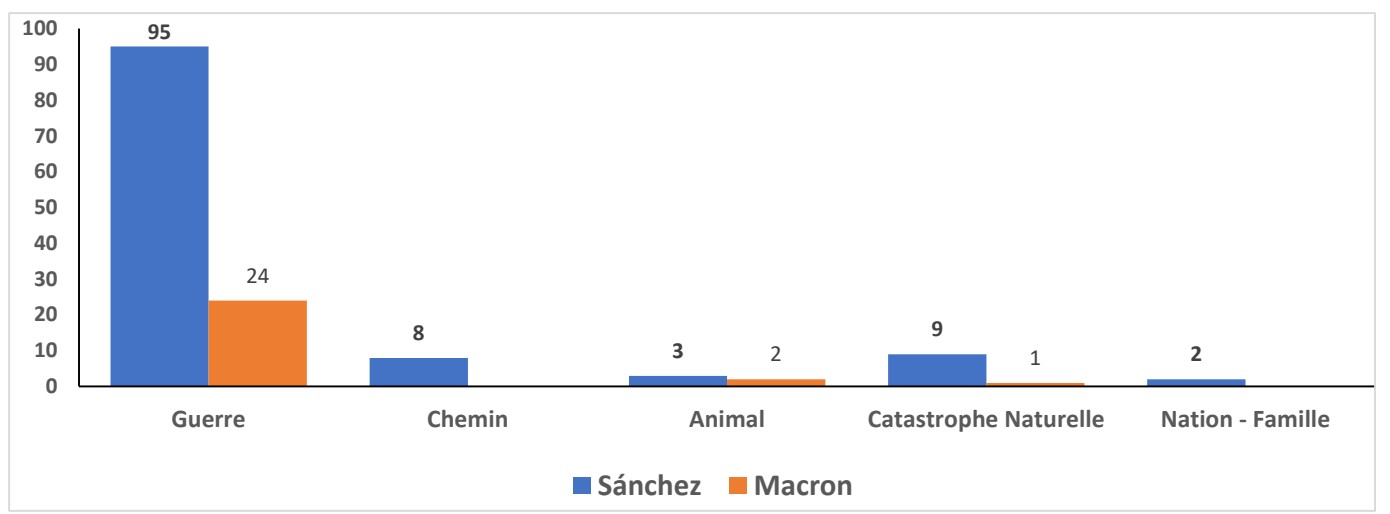

Graphique 1. Domaines sources des métaphores dans les discours de Macron et de Sánchez au sujet du COVID-19.

On retrouve 24 termes guerriers dans les discours de Macron, et 95 dans les discours de Sánchez. L'efficacité rhétorique de la métaphore guerrière est soulignée par le fait qu'elle sert à encadrer les allocutions de Sánchez, qui débutent souvent par une référence à son intention d'informer les citoyens sur l'évolution de la guerre (batalla, combate) contre le virus :

(51) Comparezco para dar cuenta de la marcha de la batalla que toda España [...] está librando contra la pandemia del COVID-19.

[Je suis ici pour rendre compte de l'état d'avancement de la bataille que toute l'Espagne [...] mène contre la pandémie de COVID-19]

Il convient de noter que la métaphore L'ACTION POUR CONTENIR LE VIRUS EST UNE GUERRE est encodée dans un large éventail de termes, notamment dans le discours de Sánchez: guerra/guerre, enemigo/ennemi, aliado, contienda, combate/combat, lucha/lutte, batalla/bataille, linea/ligne, frente/front, resistencia/résistance, arma/arme, estrategia, victoria, combatir/se battre, luchar, resistir, vencer/vaincre, ganar/gagner, derrotar/vaincre.

Nous avons relevé huit réalisations de la métaphore LE VIRUS EST UN ÊTRE HUMAIN QUI SE DÉPLACE. Elles apparaissent toutes dans les discours de Sánchez.

En ce qui concerne la métaphore LE VIRUS EST UN ANIMAL, les deux leaders y ont recours (5 réalisations au total). En revanche, la plupart des réalisations de la métaphore LE VIRUS EST UN PHÉNOMÈNE NATUREL se retrouvent dans les discours de Sánchez ( 9 expressions contre une seule pour Macron).

Finalement, la métaphore NATION-FAMILLE est seulement utilisée par Sánchez et n'est pas significative. 


\section{Conclusions}

L'analyse de la conceptualisation du virus COVID-19 met au jour un réseau métaphorique dans lequel se déploie un système de sous-métaphores liées à la mégamétaphore LE VIRUS EST UN ÊTRE HUMAIN. En examinant ces métaphores, on constate qu'il s'en dégage deux processus métaphoriques :

a) Une anthropologisation de la pandémie : on prête au virus des traits humains (le virus est un ennemi, le virus se déplace, le virus voyage)

b) Une naturalisation de la pandémie : on prête au virus des traits propres aux animaux (il est à l'affût, il mord) ou aux éléments naturels (il sème la dévastation).

Ces deux processus donnent lieu à cinq métaphores qui apparaissent dans les discours de Macron et de Sánchez : LE VIRUS EST UN ENNEMI, LE VIRUS EST UN ÊTRE HUMAIN QUI SE DÉPLACE, LE VIRUS EST UN ÊTRE HUMAIN QUI VOYAGE, LE VIRUS EST UN ANIMAL et LE VIRUS EST UNE CATASTROPHE NATURELLE. La description du COVID-19 comme un ennemi est un mappage de la métaphore L'ACTION POUR CONTENIR LE VIRUS EST UNE GUERRE. La générativité de la métaphore de la guerre est évidente dans le discours de Macron et de Sánchez. Elle crée tout un système d'analogies avec le domaine cible du virus.

L'analyse de ce réseau métaphorique met en évidence le rôle de la métaphore en tant que mécanisme cognitif et rhétorique. D'un côté, les métaphores utilisées par Macron et Sánchez pour faire référence au COVID-19 le présentent comme une entité concrète et menaçante. D'un autre côté, les métaphores du domaine de la guerre et la métaphore de la NATION-FAMILLE remplissent une fonction rhétorique dans la mesure où elles visent à revivifier des sentiments de courage et d'union nationale face à la pandémie.

\section{RÉFÉRENCES BIBLIOGRAPHIQUES}

ALDUY, Cécile (2020) : "Métaphore de Macron sur la guerre : "Cela exonère le pouvoir de ses responsabilités», interviewée par Laure Bretton. Libération, 30 mars. URL: https://www.liberation.fr/politiques/2020/03/30/metaphore-de-macron-sur-laguerre-cela-exonere-le-pouvoir-de-ses-responsabilites_1783567

BEeR, Francis A. \& Christil De LANDTSHEER [éds] (2004) : Metaphorical World Politics. East Lansing, Michigan State University Press.

BRAUMAN, Rony (2018) : Guerres humanitaires? Mensonges et intox. Paris, Textuel. URL: https://www.mjcroguet.fr/wp-content/uploads/sites/106/2020/04/rony-brauman_01.pdf

CHARTERIS-BlACK, Jonathan (2004) : Corpus Approaches to Critical Metaphor Analysis. Basingstoke, Palgrave Macmillan. 
CHARTERIS-BLACK, Jonathan (2005) : Politicians and Rhetoric: The Persuasive Power of Metaphor. Basingstoke, Palgrave Macmillan.

CHARTERIS-BLACK, Jonathan (2009) : «Metaphor and political communication», in Andreas Musolff \& Jörg Zinken (éds), Metaphor and Discourse. New York, Palgrave, 97-115.

CHARTERIS-BLACK, Jonathan (2012) : «Forensic deliberations on purposeful metaphor». Metaphor and the Social World, 2: 1, 1-21.

CHARTERIS-BLACK, Jonathan (2014) : Analysing Political Speeches. Basingstoke, Palgrave Macmillan.

Chilton, Paul (1996) : Security Metaphors: Cold War Discourse from Containment to Common European Home. Berne/New York, Peter Lang.

ChILTON, Paul \& Mikhail V. ILYN (1993) : "Metaphor in political discourse: The case of the Common European House ». Discourse and Society, 4: 1, 7-31.

Chilton, Paul \& Christina SCHÄFfner [éds] (2002): Politics as Text and Talk: Analytic Approaches to Political Discourse. Amsterdam, John Benjamins.

CUENCA, Ma. José (2020) : “¿Cómo es el coronavirus? Metáforas y símiles para una pandemia ». El Norte de Castilla, 26 avril. URL: https://www.elnortedecastilla.es/socie$\mathrm{dad} /$ salud/coronavirus-metaforas-similes-.0200426112054-ntrc.html

DE LANDSTHEER, Christil (2009) : "Collecting political meaning from the count of metaphor ", in Andreas Musolff \& Jörg Zinken (éds), Metaphor and Discourse. New York, Palgrave, 59-78.

De LandTsheER, Christil \& Ofer Feldman (2000) : Beyond Public Speech and Symbols. Explorations in the Rhetoric of Politicians and the Media. Westport, Praeger.

DE LANDTSHEER, Christil \& Elisabeth KOCH (2005) : "Metaphors and the framing of the European single currency (Euro) in and out of "Euro land" ", in R.F. Farnen et al. (éds), Democratization, Europeanization and Globalization Trends. Cross-national Analysis of Authoritarianism, Socialisation, Communication, Youth and Social Policy. Frankfurt, Peter Lang, 429-446.

Feldman, Ofer \& Christil De LANDTSHeER (1998) : Politically Speaking: A Worldwide Examination of Language Used in the Public Sphere. Westport, Praeger.

GRABER, Doris (1993) : "Political communication: Scope, progress, promise », in Ada W. Finifter (éd.), Political Science: The State of the Discipline, vol. II. Washington DC, American Political Science Association, 305-332.

JOHnSON, Mark (1987) : The Body in the Mind: The Bodily Basis of Meaning, Imagination, and Reason. Chicago, University of Chicago Press.

KRESS, Gunther \& Robert HODGE (1993) : Language as Ideology. London, Routledge.

KATZ, Albert (1996) : "On interpreting statements as metaphor or irony: Contextual heuristics and cognitive consequences ", in Jeffery S. Mio \& Albert Katz (éds), Metaphor: Implications and Applications. Mahwah, Erlbaum, 1-22.

KÖVECSES, Zoltán (2002) : Metaphor: A practical introduction. Oxford, Oxford University Press. 
LAKOFF, George (1987) : Women, Fire and Dangerous Things: What Categories Reveal about the Mind. Chicago, University of Chicago Press.

LAKOFF, George (1989) : «Philosophical speculation and cognitive science». Philosophical Psychology, 2: 1, 55-76.

LAKOFF, George (2006) : " The Contemporary Theory of Metaphor », in Dirk Geeraerts (éd), Cognitive Linguistics: Basic Readings. Berlin/New York, Mouton de Gruyter, 185-238.

LAKOFF, George \& Mark JOHnSON (1980) : Metaphors We Live By. Chicago, Chicago University Press.

LAKOFF, George \& Mark JOHNSON (1999) : Philosophy in the Flesh: The Embodied Mind and its Challenge to Western Thought. New York, Basic Books.

LAKOFF, George. \& Mark TURNER (1989) : More than Cool Reason: A Field Guide to Poetic Metaphor. Chicago, University of Chicago Press.

MUSOLFF, Andreas (1998) : " Metaphors and trains of thought: Spotting journey imagery in British and German political discourse ", in Sue Wright, Linda Hanrais and Jolyon Howorth (éds), Language, Politics, and Society. Clevedon, Multilingual Matters, 100109.

MUSOLFF, Andreas (2000) : « Political imagery of Europe: A house without exit doors? ». Journal of Multilingual and Multicultural Development, 21: 3, 216-229.

MuSOLFF, Andreas (2004) : Metaphor and Political Discourse. Analogic Reasoning in Debates about Europe. New York, Palgrave.

REAL ACADEMIA ESPAÑola (en ligne): Diccionario de la lengua española. URL: https://dle.rae.es

SEMINO, Elena \& Michela MASCI (1996) : " Politics is football Metaphor in the discourse of Silvio Berlusconi in Italy ». Discourse and Society, 7: 2, 243-269.

SHARIFIAN, Farzad \& Maryam JAMARANI (2013) : «Cultural conceptualisations and translating political discourse ", in Ana Rojo \& Iraide Ibarretxe-Antuñano (éds), Cognitive Linguistics and Translation. Berlin/New York, Mouton de Gruyter, 339-372.

SOCIÉTÉ D'ÉDITIONS LAROUSSE (2021): Dictionnaire Larousse de français. URL: https://www.larousse.fr/dictionnaires/francais-monolingue.

STEEN, Gerard J., et al. (2010) : A Method for Linguistic Metaphor Identification: From MIP to MIPVU. Amsterdam, John Benjamins.

STRAEHLE, Carolyn, et al. (1999) : "Struggle as metaphor in European Union discourses on unemployment ». Discourse and Society, 10: 1, 67-99.

THOMPSON, Seth (1996) : " Politics without metaphor is like a fish without water ", in Jeffery S. Mio and Albert Katz (éds), Metaphor: Implications and Applications. Mahwah, Erlbaum, 185-201.

VAN DiJK, Teun A. (2006) : "Politics, ideology, and discourse ", in Keith Brown (éd), Encyclopedia of Language and Linguistics. Oxford, Elsevier, 728-740. 
VOYER-LÉGER, Catherine (2020) : "Des métaphores pour mieux comprendre le coronavirus ». C'est fou, Ici Radio Canada, 30 mars. URL : https://ici.radio-canada.ca/premiere/emissions/c-est-fou/segments/chronique/161980/metaphores-coronavirus-covid-19-catherine-voyer-leger

WODAK, Ruth (éd) (1989) : Language, Power, and Ideology. Amsterdam, John Benjamins. 